\title{
Legal Culture Innovation in Chinese Regional Public Service in Sustainable Development Perspective
}

\author{
Guo Xinyu \\ School of Public Management \\ Yunnan University of Finance and Economics \\ Kunming, P.R. China, 650221 \\ (gxy0871@163.com)
}

\begin{abstract}
It's to cultivate and develop regional public service legal culture for socialism with Chinese characteristics constantly, and inject new energy for sustainable development of China to make the whole society become prosperous, democratic and civilized, finally realize the goal of law-based governance civilization, which is great significant to promote the construction of the rule of law in China, and the operation of the rule of law practice. At present, unbalanced regional legal culture development will hinder the sustainable development course. The thesis analyzes legal culture status and problems of regional public services in China now, and propose legal culture innovation in legislative concepts, legal systems and institutions, etc, as to achieve the goal of regional sustainable development.
\end{abstract}

Keywords—legal culture; regional public service; sustainable development; innovation

\section{INTRODUCTION}

An important factor that has influence on regional sustainable development is regional culture, which refers to the culture obviously related to geographical locations and evolving in history. Regional culture could reflect regional public service situations and people's participation in sustainable development. Regional sustainable development is closely coordinated with various factors like society, culture, economy and so on.

Optimizing regional public services is the objective requirement for promoting regional sustainable development, but the conflicts between actual requirements of sustainable development and backward awareness, concepts and institutions related to regional public services hinder the sustainable development course. The inconsistency legal culture is one factor that holds back the course [1].

\section{The Mechanism of Regional Public Service Legal Culture InNOvation Promoting REgional SustainABLE DEVELOPMENT}

Generally public service refers to "the public service that covers education, medical care, health, etc. and could satisfy and cover survival and development requirements of all citizens"[2]. Regional public service means analyzing public services in the angle of regional supply, while the basic institutions should be involved in general strategies for sustainable development [5]. Otherwise, it not only damages concepts of regional public service legal culture suggest legislative concepts, legal systems and legal institutions, etc. in regional public services.

In theory, legal culture does not only have the attribute of resources, but also historical succession and co-melting attributes. Legal culture is not unchanged, and its historical succession shows its developmental inevitability. Similarly the co-melting also proves the developmental innovation. Meanwhile, co-melting is also the driving force for legal culture development, too.

Sustainable development mechanism of legal culture innovation driving area in regional public services is mainly displayed in the following respects:

\section{A. Legislative Concept Innovation in Regional Public Services} Promotes Regional Sustainable Development

Legislative concept runs through legislation, and it is the important yardstick to persist always [3]. Therefore fairness and efficiency are inevitable. Fairness is one of the conditions to support sustainable development, and sustainable development is possible only when fairness develops. In pursuit of high efficiency, stress on overall revenue, comprehensive revenue and best revenue is the important embodiment of high efficiency principle in sustainable development. In the course of optimizing, strengthening or completing public services, persisting in scientific legislation and sustainable development in the course also meets inevitable requirements of scientific development concepts [4].

\section{B. Legal Institutions Innovation in Regional Public Services Promoting Regional Sustainable Development}

Institutions include formal ones, such as laws, rules and regulations; and also informal ones, such as code of conduct agreed by people to comply with collectively.

Actual regional development must be based on persisting in scientific development concepts and meeting sustainable development requirements. Legal systems and institutions are established according to actual circumstances of China, instead of regulations resulted from administrative area classifications and hard to cater for overall development. The established legal

the quality of public service supply, but also is not conducive to the protection of citizens' right to public service. Only based 
on the coordination of regional public service, formulate corresponding management mode and institutions, in order to ensure the sustainable development of regional social, cultural, economic and environmental.

\section{Legal System Innovation in Regional Public Services Promoting Regional Sustainable Development}

Sustainable development is the general strategy involving economic policies, fund mechanism, science \& technology and education, population and social security, environment protection, natural resources protection, etc. In fact, the implementation is not realized overnight. Seen from its impact on global society, sustainable development brings a revolution to the world, and the reform includes national policy integration, national institutional reform and national law innovation. Good legal system is the foundation for benign social development, and meanwhile decisive conditions to realize ambitious modernization goals. The author thinks that to build a complete legal system, sustainable development strategies should be established in constitutions; to the "environmental protection law" as the core to establish the legal system of environmental resources; meanwhile, legal systems concerning economy, civil affairs and society security should be completed and amended accordingly. Besides, criminal laws, administrative laws and procedural laws should be amended correspondingly; To establish the guiding ideology of ecological security in the science and technology law; Actively participate in the International Convention on Sustainable development.

\section{Current Status and Main Problems in Regional Public Services in China}

\section{A. Current Legal Culture in Regional Public Services}

Under the political system of central high centralization, administrative units work in their own ways. Administrative classification of China shows clear separation, partition, etc. and spans the rights scope and administration area of single administrative subject, thus resulting in quite much difference of different regional public services in different provinces, cities and even in nationality and non-nationality areas,[6] which also makes the Chinese regional public service legal culture is highly distinctive. On the whole, there are altogether three completely different legal cultures coexisting due to historic reasons: firstly Hong Kong legal culture, of which the legal institutions completely transplants British laws and displays intensive British and American law system features; secondly, Macao legal culture, which transplants Portuguese laws, displaying continental law system features ; thirdly, socialist culture which exists in Mainland China as the mainstream culture. The conflict of these three regional legal cultures becomes increasingly apparent after the return of Hong Kong and Macao, and also hinders development of our country's legal culture.

Socialism legal culture plays a key role in Mainland China, but legal culture is different in different provinces and cities, so regional legal culture conflicts are increasingly evident.

regional limitations. Therefore, it is urgent to establish and improve the public service system and promote the legalization of the service oriented government.

\section{B. Main Existing Problems}

1) Shortage of Legislative Concepts for Sustainable Regional Public Service Development

In terms of legislative concepts, the idea that law exists only as a tool is held by some people. Current systems are severely unmatched with actual development and drag the social development course [7], mainly displaying in the following respects:

Extreme unbalance of regional development, including the regional ecological and regional development is mainly displayed in the following respects: some areas are teemed with resources, while some other areas are in shortage; some areas own all conditions for good development, while some other areas are in the predicament of low output value, severe pollution, etc. All of these unfair on regional development, so that different regions appear very different in the pursuit of sustainable development outcomes.

The unfair legal policies lie in preparation and implementation, i.e. formulating and implementing policies. In terms of policy formulation, there are unfair policies in terms of prices, taxation, industry, investment, labor, etc. In terms of policy implementation, different policies are executed in different areas and people, i.e. developed areas and backward areas, the rich and the poor; so laws are unfair and unreasonable. Laws are not enforced justly in front of everyone, because of different people, different places, different things, different powers and money, etc. in the enforcement of law deviation.

\section{2) Incomplete Legal Institutions in Regional Public} Services

Firstly, only some policy guidance and development planning guide the regional development in current stage, which are not laws, so they don't have oughtness of laws and therefore hinder overall regional development. Secondly, regional development is inconsistent due to some reasons, such as terms of offices of leaders. Besides, local legislation is more active than central legislation, so there are legislative conflicts between national and local levels. In order to realize sustainable regional development, legal institutions meeting actual circumstances of a specific area should be formulated under the condition of fully understanding the regional supply and demand.

Seen from the current situations, local governments of every level have made explorations and attempts for regional sustainable development. Basic modes are: (1) Legislation in the form of governmental regulations and rules, for example "Service Regulations of Hunan Province". (2) System guarantee by making governmental planning, such as "Basic Public Service Equitable Planning of Guangdong Province" (2009-2020). It cannot be denied that ways above can meet regional development requirements temporarily, but it should be realized that local legislative levels are limited and impossible to get all respects of life involved. Moreover, these legislations have contradictions and conflicts generally due to

3) Incomplete Legal System in Regional Public Services

Firstly, sustainable development strategies are not established in the current constitution. Secondly, China doesn't 
have a basic law to guarantee implementation of regional sustainable development. The basic law is able to coordinate with public services of all areas to realize overall regional development. Besides, China's civil, economy, social security laws and regulations, etc are not from the concept of regional sustainable development to set up the relevant promotion of regional public service supply system. Meanwhile, as the sustainable development legislative system of regional public services is incomplete, there are inadequate legal standards for public service providing standard, scope, ways, safeguard measures, etc.

As a result, current Chinese legislative systems cannot support regional sustainable development, and should be completed in the respects above.

\section{Legal Culture InNOVAtion IN Chinese Regional Public Services}

\section{A. Concept Innovation in Regional Public Services}

Creative concepts are guiding and driving legal culture development. They not only guide legal culture innovation, but also promote legal culture forming. Concept innovation should be carried out in the following respects:

Firstly, establish modern legal concepts. The modern legal concepts here are state governance concepts and legal concepts suitable with modern economic and social life and the supremacy of law and power restricting as the core content of the governing philosophy and legal concepts., including cultural transition such ideology, values, morality and ethnics, and they are core forces to promote modern legal culture concept innovation.

Secondly, establish the legal modernization concept. The so-called legal modernization is virtually institutional modernization, including legal institutions, rules and procedures involving all social life respects, that's to say, not only political economy, but also social culture. In modern China, only when pragmatic and progressive legal reforms are persistently pushed forward, and institutions innovation is carried out in order, the legal development of the Chinese model is improved and optimized, legal development will gain long-lasting revolutionary motivation.

Thirdly, establish the sustainable development principles [8]. There are many requirements for regional sustainable development. It is not the ultimate requirement of sustainable development to narrow down regional economic gap, and the ultimate goal is to ensure coordinated development of regional society, culture, economy and environment.

\section{B. Complete the Legal institutions for Regional Public Services}

Most western countries launch public service legislation activities in reform, so that public services "have laws to abide by". Even in western countries focused on unwritten case laws such as the U.K., written laws are stipulated concerning public services, such as "Telecommunications Act" and "Water Supply Act" of the U. K. Targeting at defects of legal systems for public service organizations, including issues of governments and social organizations in public service legislation, our country's public service organization legal system can be completed in the following respects:

1) Complete the Legal Institutions for Government Public Services

Firstly, define the duties and responsibilities of government public services. On one hand, National People's Congress should define rights and liabilities of the government in the constitution. On the other hand, allocate reasonable public service responsibilities of central and local governments in the constitution, and safeguard basic rights of citizens effectively only in this way.

Secondly, guide governments to implement public services by way of laws. On one hand, by formulating laws, guide governments to concentrate their services areas within the framework involving providing infrastructure, establishing fair public service systems, building public service management, etc. On the other hand, under the guidance of laws, public service providers including enterprises manage themselves.

2) Complete Procedure and Legal Institutions of Public Services

Firstly, standardize "legislation" of public service procedures via legal standards of different levels. Secondly, classify public services into two categories via public service procedure codes. The code provides rigorous stipulations about procedures that may have significant impact on rights and interests of citizens, and public sectors should implement the code rigorously; as for other public services, public sectors are given the discretion.

\section{Complete the Legal System of Regional Public Services}

In order to provide the most appropriate public services for the public, most western countries adopt legal systems of different origins with a combination of multi-level legislative authority, administrative decree, judicial precedent, etc. Therefore, it is necessary for our country to build a complete public service legal system so as to complete public service legislation.

\section{1) Prepare Uniform Legal Standards for Public Services}

At present, the law has been the main means to administrate national and social affairs. Relatively complete public service legal systems of worldwide countries are all compulsorily carried out by national legislation. Completing public service systems by legislation will lay a foundation for the long-term development of public services,

The current, it is necessary to further complete legal institutions of Chinese public services, accelerate the legislation course, and ensure the good development. Based on actual circumstances of China at present, "Basic Law for Public Services" should be formulated as soon as possible, in a bid to define fundamental principles of public services on the whole, reasonably classify duties and responsibilities of public service responsibility subjects, and better regulate their operation and development.

2) Complete Different Levels of Public Service Legislation

In terms of legal levels of public services, improvements should be made in the following two respects: firstly, on the 
longitudinal level of legal systems, integrate current laws, regulations and policies as soon as possible, clear relevant laws, regulations and policies, advance relatively mature laws and regulations, policies into basic laws by way of legislation in National People's Congress, and improve their authority and uniformity. Secondly, on the horizontal level of legal systems, complete the standardization of public service providing subjects, fund sources and management systems, further define detailed responsibilities to be borne by governments and sectors of all levels, and meanwhile formulate responsibility assigning mechanism, such as restriction and punishment system for responsibility fulfillment failure, so that every step will be put into practice.

Besides, active participation of the public should be engaged in regional public service legislation, and the legislative course should be open and transparent to the public. For instance, in the U. K., "the formulation of laws respects the expression of various interest viewpoints, encourages participation of political and social groups, and attaches much importance to the transparency during the entire legislative procedure", and effective "consultation mechanism" is established. Based on such "consultation mechanism", the public service legislation is accepted more and more widely.

\section{CONCLUSIONS}

In a word, regional public services are involved in every respect of life, and it is able to safeguard sustainable development of regional public services to constantly innovate legislative concepts and build a legal system of multiple levels with the combination of diverse legal systems. We are expected to constantly cultivate and develop regional public service legal culture for socialism with Chinese characteristics and inject new energy for sustainable development of China based on inheriting history and referring to overseas reasonable and advanced legal culture, so that the whole society will become prosperous, democratic and civilized, and finally realize the goal of law-based governance civilization. This is of great significance to promote the construction of the rule of law in China, and the operation of the rule of law practice.

\section{REFERENCES}

[1] Sun Guangyan, Linking Ways of Traditional Legal Culture and Legal Modernization [J]. Academic Exchange, 2006,(4) P45-48. (In Chinese)

[2] Zhang Xiaojie, Equalization of Urbanization, Regional Gap and Basic Public Services [J]. Economic System Reform, 2010,(2) P118-122. (In Chinese)

[3] Feng Nianhua, Theory and Empirical Study on Regional Sustainable Development Theory [D]. Nanjing Agricultural University, 2003. (In Chinese)

[4] Peng Rongsheng, Study on Connotation, Mechanism and Evaluation of Regional Economic Coordinated Development [D]. Henan University, 2007 (In Chinese)

[5] Li Rong, legislative Conflicts and Ways of Solutions [D]. Yantai University, 2007 (In Chinese)

[6] Zhang Bo, Study on Administrative Legal Culture Innovation during Social Transition [J]. Guihai Tribune, 2005,(3) P58-60. (In Chinese)

[7] Yang Xingjuan. Promote Legal Construction of Sustainable Development [J]. Development Research, 2005,(3) P61-62. (In Chinese)

[8] Liu Tongjun, Legal Culture Interpretation of Farmers' Rights Development under New Urbanization Background [J]. Study \& Exploration, 2014, (2) P63-70. (In Chinese) 